\title{
Trisomy 8-Associated Intestinal Behcet's Disease That Achieved Complete Remission With Mesalazine
}

\author{
Satoshi Tanida ${ }^{\mathrm{a}, \mathrm{b}}$, Keiji Ozeki ${ }^{\mathrm{a}}$, Tsutomu Mizoshita ${ }^{\mathrm{a}}$, Mamoru Tanika ${ }^{\mathrm{a}}$, \\ Hirotada Nishie ${ }^{a}$, Yasuyuki Okamoto a, Takaya Shimura ${ }^{a}$, \\ Eiji Kubota ${ }^{a}$, Hiromi Kataoka ${ }^{a}$
}

\begin{abstract}
A 39-year-old man was referred to our hospital because of ileocecal ulcer and pancytopenia. Past medical history included psoriatic arthritis and acne vulgaris. Physical examination findings showed recurrent oral ulcerations and acneiform eruptions on his body. Colonoscopy confirmed the presence of an ulcer at the ileocecal valve. Human leukocyte antigen was positive for B51. Based on the bone marrow findings of hypercellularity accompanied by trilineage dysplastic changes and cytogenetic findings of 47,XY,dup(1)(q21q32), idem +8 , a definite diagnosis of intestinal Behcet's disease (BD), incomplete type, associated with myelodysplastic syndrome (MDS) with positivity for trisomy 8 was finally confirmed. Treatment of intestinal BD with mesalazine at 3,000 $\mathrm{mg}$ daily induced complete ulcer healing after 4 months. Thereafter, two cycles of azacytidine was administered, followed by bone marrow transplantation. The patient has done well with continuous healing of the ulcer for a year. Differentiating episodic MDS with positivity for trisomy 8 from drug-induced MDS by examination of the bone marrow and the cytogenetic changes is indispensable. Intestinal BD patients who develop pancytopenia would probably need sufficient doses of mesalazine for treatment.
\end{abstract}

Keywords: Pancytopenia; Myelodysplastic syndrome; HLAB51; U1cer healing

\section{Introduction}

Behcet's disease (BD) is a chronic inflammatory disease characterized by repeated periods of remission and deterioration of oral and genital ulcers, along with ocular or skin involve-

Manuscript submitted April 13, 2018, accepted June 12, 2018

aDepartment of Gastroenterology and Metabolism, Nagoya City University Graduate School of Medical Sciences, 1 Kawasumi, Mizuho-cho, Mizuho-ku, Nagoya, Aichi 467-8601, Japan

${ }^{\mathrm{b}}$ Corresponding Author: Satoshi Tanida, Department of Gastroenterology and Metabolism, Nagoya City University Graduate School of Medical Sciences, 1 Kawasumi, Mizuho-cho, Mizuho-ku, Nagoya, Aichi 467-8601, Japan.

Email: stanida@med.nagoya-cu.ac.jp

doi: https://doi.org/10.14740/jmc3082w ment [1]. Intestinal BD, which is a specific subtype of BD with gastrointestinal (GI) involvement, accounts for approximately $3-16 \%$ of $\mathrm{BD}$ cases [2]. BD that is associated with bone marrow failure, including myelodysplastic syndrome (MDS) and anaplastic anemia, frequently has GI involvement $[3,4]$. Moreover, concomitant trisomy 8 reportedly accounted for 54 $86 \%$ of cases with $\mathrm{BD}$ with bone marrow failure [4-6].

Conventionally, the pharmacological treatments of BD include 5-aminosalicylic acid, systemic corticosteroids and immunosuppressive agents, such as thiopurines [7-9]. However, many patients fail to respond to these treatments [10]. Patients with intestinal BD have been demonstrated to respond effectively and safely to adalimumab and infliximab [11, 12], but most of them who associated MDS and concomitant trisomy 8 have experienced refractoriness to conventional treatment [13]. For these intractable cases, adalimumab and azacytidine were reportedly effective as treatment for the MDS [14, 15]. However, no information is currently available regarding the achievement of complete remission with mesalazine for intestinal BD associated with MDS and concomitant trisomy 8 . Herein we reported a case of intestinal BD achieving complete remission with mesalazine. Differentiating MDS with positivity for trisomy 8 from drug-induced MDS by examination of the bone marrow and the cytogenetic changes is indispensable. Intestinal BD patients who develop pancytopenia would probably need sufficient doses of mesalazine for treatment.

\section{Case Report}

The patient was a 39-year-old man who was referred to our hospital because of ileocecal ulcer, moderate right lower abdominal pain and pancytopenia. He was diagnosed as psoriatic arthritis 2 years ago because of pain, stiffness and, swelling of a few joints including the knees and ankles. Combination therapy with adalimumab and methotrexate was started, but it had to be discontinued because of the emergence of pancytopenia after 1 year; at that time, he was also diagnosed as acne vulgaris. The patient had no history of genital ulceration and uveitis. Physical findings revealed recurrent oral ulcerations and acneiform eruptions on his body with slight pallor but without fever. Laboratory investigations showed: white blood cell count, $1,700 / \mu \mathrm{L}$; red blood cell count, $339 \times 10^{4} / \mu \mathrm{L}$; hemoglobin, $10.0 \mathrm{~g} / \mathrm{dL}$; platelet count, $3.3 \times 10^{4} / \mu \mathrm{L}$; myelocyte, 
$4 \%$; metamyelocyte, $2 \%$; total protein, $7.1 \mathrm{~g} / \mathrm{dL}$; albumin, 4.0 $\mathrm{mg} / \mathrm{dL}$; lactate dehydrogenase (LDH), $272 \mathrm{IU} / \mathrm{L}$; aspartate aminotransferase, $12 \mathrm{IU} / \mathrm{L}$; alanine aminotransferase, $9 \mathrm{IU} / \mathrm{L}$; immunoglobulin (Ig) G, 1,208 mg/dL; IgA, $155 \mathrm{mg} / \mathrm{dL} ; \mathrm{IgM}$, $125 \mathrm{mg} / \mathrm{dL}$; $\mathrm{CH} 50,75 \mathrm{U} / \mathrm{L}$; and C-reactive protein, $5.8 \mathrm{mg} /$ dL. Pancytopenia with a left shift was seen. Human leukocyte antigens B51 and B27 were positive. Negative results were obtained from tests for $(1 \rightarrow 3)-\beta$-D-glucan, QuantiFERON and cytomegalovirus antigenemia C-7HRP (Table 1). Colonoscopy and pathologic examination of biopsy specimen from the ulcer (Fig. 1) showed the moderate inflammatory infiltrates composed of neutrophils and mononuclear cells and necrosis in the submucosa and regenerative epithelia. According to diagnostic criteria defined by the BD Research Committee of Japan, the patient was diagnosed as intestinal BD, incomplete-type, based on the presence of two major features of recurrent oral ulceration and typical skin lesions, and two minor features of arthritis without deformity and ileocecal ulcer [16]. For the treatment of the ileocecal ulcer from intestinal $\mathrm{BD}$, mesalazine at 3,000 mg daily was immediately started. Four months later, colonoscopy showed an ulcer scar at the ileocecal valve.

In addition, evaluation of the pancytopenia with bone marrow study showed hypercellularity with trilineage dysplastic changes, particularly with increased number of megakaryocytes that were small in size and, in part, had multiple dispersed nuclei. Cytogenetic analysis exhibited 47,XY,dup(1) (q21q32), idem +8 (Fig. 2). Based on these findings, a definite diagnosis of intestinal $\mathrm{BD}$, incomplete-type, associated with MDS and positivity for trisomy 8 , was finally confirmed. After healing of the ileocecal ulcer was achieved, two cycles of azacytidine were administered and, subsequently bone marrow transplantation was performed. The patient has done well with continuous ulcer healing at the ileocecal valve for a year.

\section{Discussion}

In this report, we presented herein a case of intestinal BD associated with MDS and positivity for trisomy 8 that achieved complete ulcer healing after administration of mesalazine for 4 months.

The contributory causes of MDS development secondary to intestinal BD include drug-induced MDS and episodic MDS involving trisomy 8 . Treatment-induced immunosuppression has been suspected to increase the risk of malignancy [17]. In the present case, the combination therapy of adalimumab and methotrexate for psoriatic arthritis was discontinued when pancytopenia was detected because of the possibility of developing adverse events such as hematological malignancies. Indeed, monotherapy with anti-tumor necrosis factor (TNF)- $\alpha$ antagonists or methotrexate is known to increase the risk for melanomatous and non-melanomatous skin cancers, but its risk for hematological disorders, such as MDS and lymphoproliferative diseases, is not clear [18]. Moreover, a recent metaanalysis on patients who were given immunosuppressive therapy for immuno-mediated diseases after a prior malignancy showed that the incidence rates of new primary cancer (i.e.,
Table 1. Laboratory findings upon the initial visit

\begin{tabular}{|c|c|}
\hline \multicolumn{2}{|l|}{ Hematology } \\
\hline WBC & $1,700 / \mu \mathrm{L}$ \\
\hline Myelocyte & $4 \%$ \\
\hline Metamyelocyte & $2 \%$ \\
\hline Stab neutrophil & $8 \%$ \\
\hline Segmented neutrophil & $20 \%$ \\
\hline $\mathrm{RBC}$ & $339 \times 10^{4} / \mu \mathrm{L}$ \\
\hline $\mathrm{Hb}$ & $10.0 \mathrm{~g} / \mathrm{dL}$ \\
\hline $\mathrm{Ht}$ & $31.9 \%$ \\
\hline $\mathrm{MCV}$ & $94.1 \mathrm{fL}$ \\
\hline $\mathrm{MCH}$ & $29.5 \mathrm{pg}$ \\
\hline PLT & $3.3 \times 10^{4} / \mu \mathrm{L}$ \\
\hline \multicolumn{2}{|l|}{ Serum biochemistry } \\
\hline $\mathrm{TP}$ & $7.1 \mathrm{~g} / \mathrm{dL}$ \\
\hline Alb & $4.0 \mathrm{~g} / \mathrm{dL}$ \\
\hline AST & $12 \mathrm{U} / \mathrm{L}$ \\
\hline ALT & $9 \mathrm{U} / \mathrm{L}$ \\
\hline $\mathrm{LDH}$ & $272 \mathrm{U} / \mathrm{L}$ \\
\hline$\gamma$-GTP & $25 \mathrm{mg} / \mathrm{dL}$ \\
\hline FBS & $100 \mathrm{mg} / \mathrm{dL}$ \\
\hline TCHO & $159 \mathrm{mg} / \mathrm{dL}$ \\
\hline TG & $183 \mathrm{mg} / \mathrm{dL}$ \\
\hline Crea & $0.66 \mathrm{mg} / \mathrm{dL}$ \\
\hline BUN & $9.0 \mathrm{mg} / \mathrm{dL}$ \\
\hline $\mathrm{Na}$ & $143 \mathrm{mmol} / \mathrm{L}$ \\
\hline $\mathrm{K}$ & $4.1 \mathrm{mmol} / \mathrm{L}$ \\
\hline $\mathrm{Cl}$ & $106 \mathrm{mmol} / \mathrm{L}$ \\
\hline $\mathrm{Ca}$ & $9.1 \mathrm{mg} / \mathrm{dL}$ \\
\hline CRP & $5.8 \mathrm{mg} / \mathrm{dL}$ \\
\hline \multicolumn{2}{|l|}{ Serologic tests } \\
\hline IgG & $1,208 \mathrm{mg} / \mathrm{dL}$ \\
\hline $\operatorname{Ig} \mathrm{A}$ & $155 \mathrm{mg} / \mathrm{dL}$ \\
\hline $\operatorname{IgM}$ & $125 \mathrm{mg} / \mathrm{dL}$ \\
\hline CH50 & $75 \mathrm{U} / \mathrm{mL}$ \\
\hline C-7HRP & Negative \\
\hline$(1 \rightarrow 3)-\beta$-D-glucan & Negative \\
\hline QuantiFERON & Negative \\
\hline Anti-nuclear Ab & Negative \\
\hline HLA B51, B27 & Positive \\
\hline
\end{tabular}

skin cancer, melanoma, hematological malignancy, breast and solid cancers) were not significantly different among patients who did not receive immunosuppression, those who receive anti-TNF- $\alpha$ antagonists and those who received conventional immunosuppression with thiopurines and methotrexate [19]. 


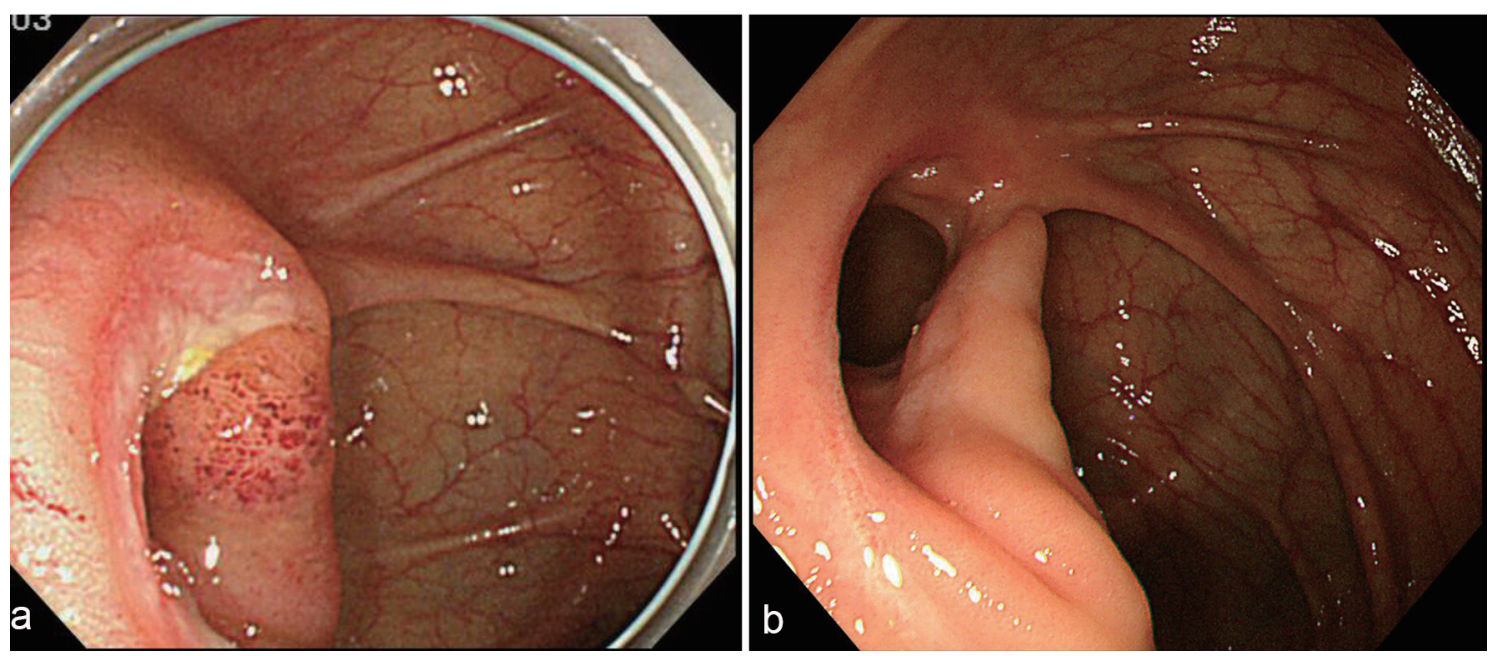

Figure 1. Colonoscopy findings. (a) Before treatment, there is an actively large ulcer at the ileocecal valve; (b) at 4 months after the intake of mesalazine, ulcer scar is seen.

In addition, accumulated data did not show evidence that anti-TNF- $\alpha$ antagonists or conventional immunosuppression induced chromosomal duplications and trisomy. Analysis of 39 cases of BD associated with MDS has demonstrated the presence of the trisomy 8 allele in $6.5-16.3 \%$ of patients with primary MDS $[20,21]$. In addition, trisomy 8 in MDS cases complicated with $\mathrm{BD}$ is a very common chromosomal abnormality $[4,5]$.

Interestingly, dup(1)(q21q32) as a sole cytogenetic event was reportedly associated with a leukemic transformation in
MDS, and trisomy 8 was likely to be secondary to this chromosomal duplication [22]. This suggested that the presence of $\operatorname{dup}(1)(\mathrm{q} 21 \mathrm{q} 32)$ may be a triggering factor for trisomy 8 . Based on the above, development of MDS upon the emergence of pancytopenia was expected. The GI involvement in patients with intestinal BD associated with MDS with positivity for trisomy 8 is generally refractory to conventional medical therapies [13].

Anti-TNF- $\alpha$ antagonists, azacytidine and bone marrow transplantation have been reported to be effective for these in-

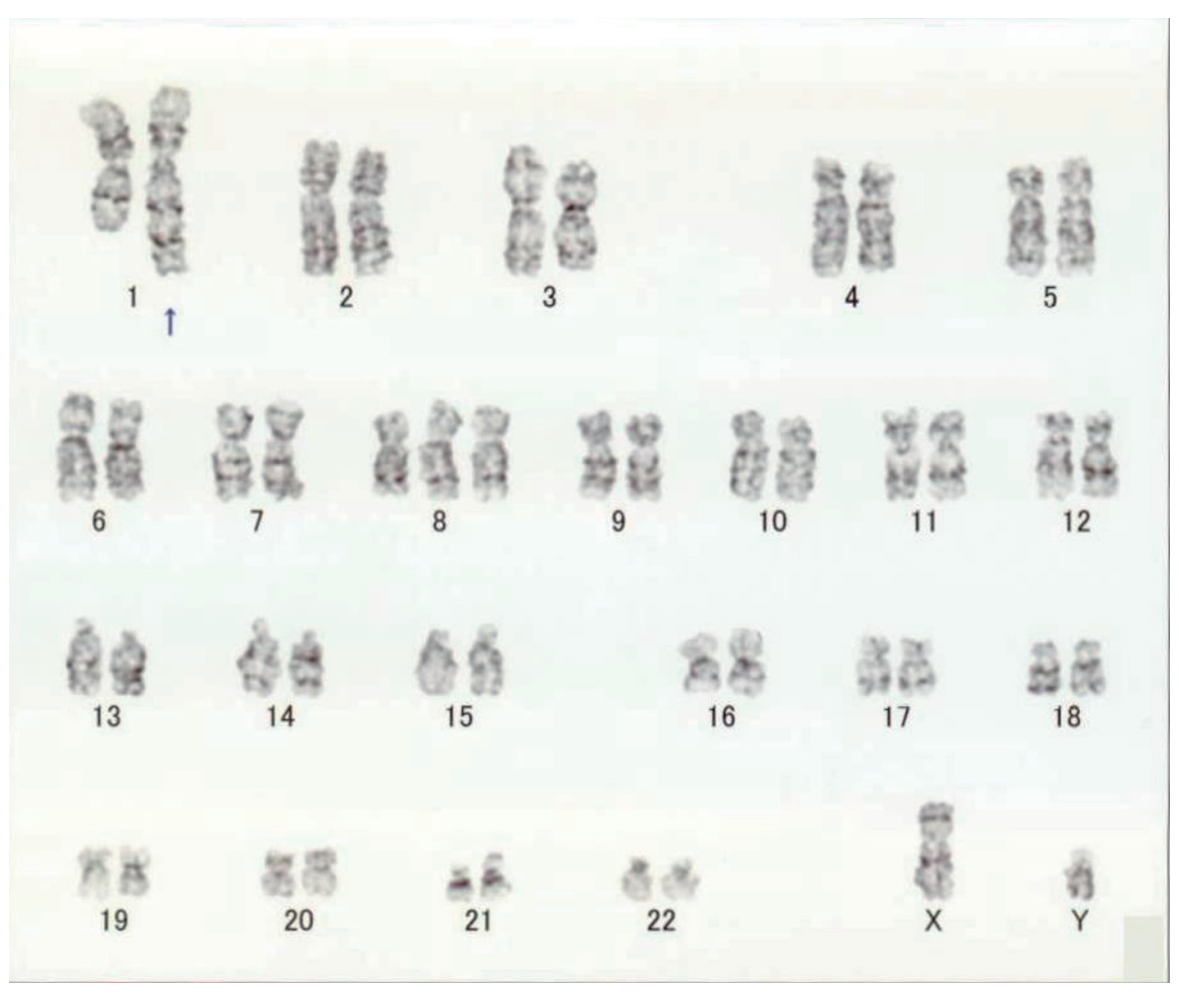

Figure 2. Cytogenetic finding. Cytogenetic analysis shows 47,XY,dup(1)(q21q32), idem+8. 
tractable cases [13-15]. However, in the present case, the GI involvement successfully responded to mesalazine at 3,000 mg. To our best knowledge, this was the first case of mesalazine therapy for a patient with intestinal BD associated with MDS and positivity for trisomy 8 . Further study on a larger number of patients is necessary to validate the predictive factors of response to treatment, including mesalazine, anti-TNF- $\alpha$ antagonists and azacytidine.

In conclusion, upon the emergence of pancytopenia in patients with intestinal $\mathrm{BD}$, examining the bone marrow and the cytogenetic changes to differentiate episodic MDS with positivity for trisomy 8 from drug-induced MDS is needed; moreover, treatment with sufficient doses of mesalazine might be helpful.

\section{Conflict of Interest}

The authors declare that there are no conflicts of interest regarding the publication of this paper.

\section{Abbreviations}

HLA: human leukocyte antigen; BD: Behcet's disease; MDS: myelodysplastic syndrome; GI: gastrointestinal; LDH: lactate dehydrogenase; Ig: immunoglobulin

\section{References}

1. Saadoun D, Wechsler B. Behcet's disease. Orphanet J Rare Dis. 2012;7:20.

2. Sakane T, Takeno M, Suzuki N, Inaba G. Behcet's disease. N Engl J Med. 1999;341(17):1284-1291.

3. Esatoglu SN, Hatemi G, Salihoglu A, Hatemi I, Soysal T, Celik AF. A reappraisal of the association between Behcet's disease, myelodysplastic syndrome and the presence of trisomy 8: a systematic literature review. Clin Exp Rheumatol. 2015;33(6 Suppl 94):S145-151.

4. Ahn JK, Cha HS, Koh EM, Kim SH, Kim YG, Lee CK, Yoo B. Behcet's disease associated with bone marrow failure in Korean patients: clinical characteristics and the association of intestinal ulceration and trisomy 8. Rheumatology (Oxford). 2008;47(8):1228-1230.

5. Tada Y, Koarada S, Haruta Y, Mitamura M, Ohta A, Nagasawa K. The association of Behcet's disease with myelodysplastic syndrome in Japan: a review of the literature. Clin Exp Rheumatol. 2006;24(5 Suppl 42):S115-119.

6. Kawabata H, Sawaki T, Kawanami T, Shimoyama K, Karasawa H, Fukushima T, Masaki Y, et al. Myelodysplastic syndrome complicated with inflammatory intestinal ulcers: significance of trisomy 8. Intern Med. 2006;45(22):1309-1314.

7. Hisamatsu T, Ueno F, Matsumoto T, Kobayashi K, Koganei K, Kunisaki R, Hirai F, et al. The 2nd edition of consensus statements for the diagnosis and management of intestinal Behcet's disease: indication of anti-TNFalpha monoclonal antibodies. J Gastroenterol. 2014;49(1):156162.

8. Jung YS, Hong SP, Kim TI, Kim WH, Cheon JH. Longterm clinical outcomes and factors predictive of relapse after 5-aminosalicylate or sulfasalazine therapy in patients with intestinal Behcet disease. J Clin Gastroenterol. 2012;46(5):e38-45.

9. Hatemi G, Silman A, Bang D, Bodaghi B, Chamberlain AM, Gul A, Houman MH, et al. EULAR recommendations for the management of Behcet disease. Ann Rheum Dis. 2008;67(12):1656-1662.

10. Comarmond C, Wechsler B, Cacoub P, Saadoun D. Approaches to immunosuppression in Behcet's disease. Immunotherapy. 2013;5(7):743-754.

11. Tanida S, Inoue N, Kobayashi K, Naganuma M, Hirai F, Iizuka B, Watanabe K, et al. Adalimumab for the treatment of Japanese patients with intestinal Behcet's disease. Clin Gastroenterol Hepatol. 2015;13(5):940-948 e943.

12. Hibi T, Hirohata S, Kikuchi H, Tateishi U, Sato N, Ozaki $\mathrm{K}$, Kondo K, et al. Infliximab therapy for intestinal, neurological, and vascular involvement in Behcet disease: Efficacy, safety, and pharmacokinetics in a multicenter, prospective, open-label, single-arm phase 3 study. Medicine (Baltimore). 2016;95(24):e3863.

13. Soysal T, Salihoglu A, Esatoglu SN, Gulturk E, Eskazan AE, Hatemi G, Hatemi I, et al. Bone marrow transplantation for Behcet's disease: a case report and systematic review of the literature. Rheumatology (Oxford). 2014;53(6):1136-1141.

14. Kimura M, Tsuji Y, Iwai M, Inagaki M, Madian A, Yoshino T, Matsuura $\mathrm{M}$, et al. Usefulness of adalimumab for treating a case of intestinal Behcet's disease with trisomy 8 myelodysplastic syndrome. Intest Res. 2015;13(2):166169.

15. Tanaka H, Shimizu N, Tougasaki E, Kawajiri C, Hashimoto S, Takeda Y, Sakai S, et al. Successful treatment by azacitidine therapy of intestinal Behcet's disease associated with myelodysplastic syndrome. Int J Hematol. 2013;97(4):520-524.

16. Japan BsDRCo. Behcet's disease: guide to diagnosis of Behcet's disease. Jpn J Ophthalmol. 1974;18:291-294.

17. Singh JA, Wells GA, Christensen R, Tanjong Ghogomu E, Maxwell L, Macdonald JK, Filippini G, et al. Adverse effects of biologics: a network meta-analysis and Cochrane overview. Cochrane Database Syst Rev. 2011;2:CD008794.

18. Scott FI, Mamtani R, Brensinger CM, Haynes K, ChiesaFuxench ZC, Zhang J, Chen L, et al. Risk of nonmelanoma skin cancer associated with the use of immunosuppressant and biologic agents in patients with a history of autoimmune disease and nonmelanoma skin cancer. JAMA Dermatol. 2016;152(2):164-172.

19. Shelton E, Laharie D, Scott FI, Mamtani R, Lewis JD, Colombel JF, Ananthakrishnan AN. Cancer recurrence following immune-suppressive therapies in patients with immune-mediated diseases: a systematic review and meta-analysis. Gastroenterology. 2016;151(1):97-109 e104.

20. Riccardi VM. Trisomy 8: an international study of 70 patients. Birth Defects Orig Artic Ser. 1977;13(3C):171- 
184.

21. Chen G, Zeng W, Miyazato A, Billings E, Maciejewski JP, Kajigaya S, Sloand EM, et al. Distinctive gene expression profiles of CD34 cells from patients with myelodysplastic syndrome characterized by specific chromosomal abnormalities. Blood. 2004;104(13):4210-4218.

22. Alfaro R, Perez-Granero A, Duran MA, Besalduch J, Rosell J, Bernues M. dup(1)(q21q32) as a sole cytogenetic event is associated to a leukemic transformation in myelodysplastic syndromes. Leuk Res. 2008;32(1):159-161. 